\title{
What Does Ectoine Do to DNA? A Molecular-Scale Picture of Compatible Solute - Biopolymer Interactions
}

\section{SUPPORTING INFORAMTION}

Julia Wittmar, ${ }^{1 \S}$ Susann Meyer, ${ }^{2 \S}$ Thorben Sieling ${ }^{1}$, Jörg Kunte, ${ }^{2 *}$ Jens Smiatek $^{3}$ and Izabella Brand ${ }^{1 *}$

${ }^{1}$ Department of Chemistry, Carl von Ossietzky University of Oldenburg, 26111 Oldenburg, Germany

${ }^{2}$ Biodeterioration and Reference Organisms, Bundesanstalt für Materialforschung und prüfung BAM, 12205 Berlin, Germany

${ }^{3}$ Institute for Computational Physics, University of Stuttgart, D-70569 Stuttgart, Germany

$\S$ Current address: Institute of Cell Dynamics and Imaging, Westfälische Wilhelms Universität Münster, 48149 Münster, Germany

$\S \S$ Current address: Bundesanstalt für Arbeitsschutz und Arbeitsmedizin, Nöldnerstr. 40-42, 10317 Berlin, Germany

* Corresponding authors:

Izabella Brand: izabella.brand@uni-oldenburg.de

Jörg Kunte: $\underline{\text { hans-joerg.kunte@bam.de }}$

\section{Contents:}

S1. XP- spectra of ssDNA and dsDNA monolayers on the Au surface.

S2. Calculated vibrations

S3. PM IRRA spectra of dsDNA monolayers in the absence and presence of ectoine in phosphate buffer solution.

S4. Fourier self-deconvolution of the IR spectra of dsDNA monolayers

S6. Raw PM IRRA spectra of the dsDNA monolayers in the $1800-1000 \mathrm{~cm}^{-1}$ spectral region .

S7. Integral intensity of an IR absorption mode in PM IRRAS 
Figure S1 shows survey spectra of the freshly prepared ss $(\mathrm{CG})_{20}-65 \%$ (1) and ds $(\mathrm{dCdG})_{20}-65 \%$ (2) and after 4 weeks of the storage of the $\mathrm{ds}(\mathrm{dCdG})_{20}-65 \%$ SAMs in $\mathrm{H}_{2} \mathrm{O}(3)$ and $0.1 \mathrm{M}$ ectoine solution (4).

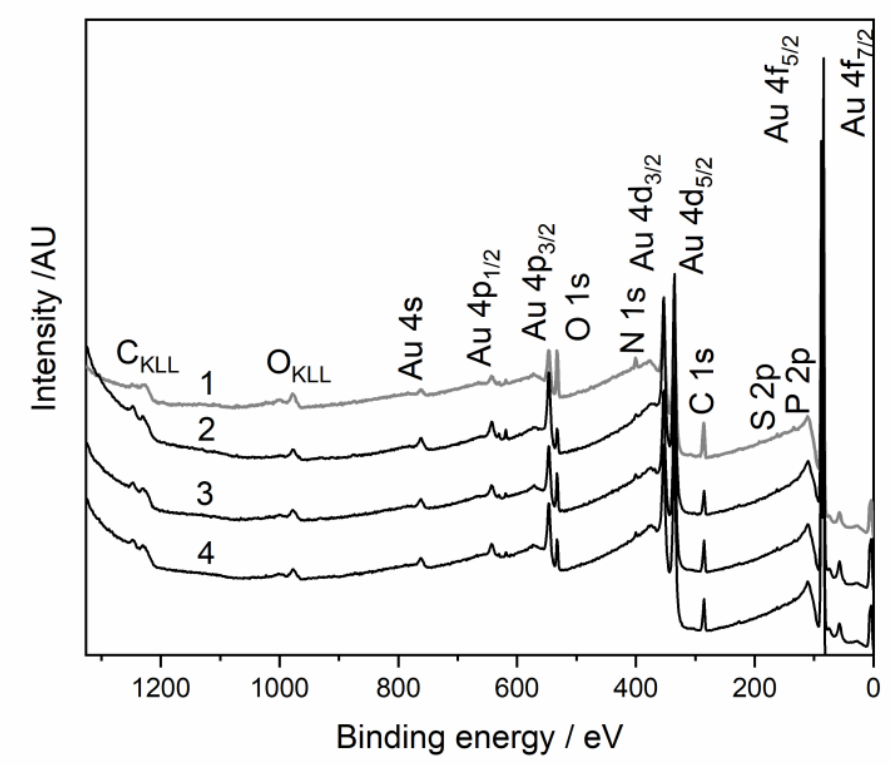

Figure S1. Survey XP spectra of freshly prepared 1) ss $(\mathrm{CG})_{20}-65 \%$ and 2) ds(dCdG) ${ }_{20}-65 \%$ monolayer and of ds $(\mathrm{dCdG})_{20}-65 \%$ monolayer stored for 4 weeks in 3) $\mathrm{H}_{2} \mathrm{O}$ and 4) $0.1 \mathrm{M}$ ectoine solution.

XP survey spectra of these SAMs reveal the presence of $\mathrm{Au}, \mathrm{C}, \mathrm{O}, \mathrm{N}, \mathrm{P}$ and $\mathrm{S}$ elements in all samples, confirming the element composition of DNA and 1-mercapto-6hexanol $\left(\mathrm{SC}_{6} \mathrm{OH}\right)$ monolayers on the gold surface.

High-resolution S 2p XP spectra of $\mathrm{ss}(\mathrm{dCdG})_{20}-65 \%$ and $\mathrm{ds}(\mathrm{dCdG})_{20}-65 \%$ monolayers are shown in Figure $S 2$. The $S$ 2p line arises from the anchor thiol groups in the $(\mathrm{dCdG})_{20}-65 \%$ DNA fragments and $\mathrm{SC}_{6} \mathrm{OH}$. 


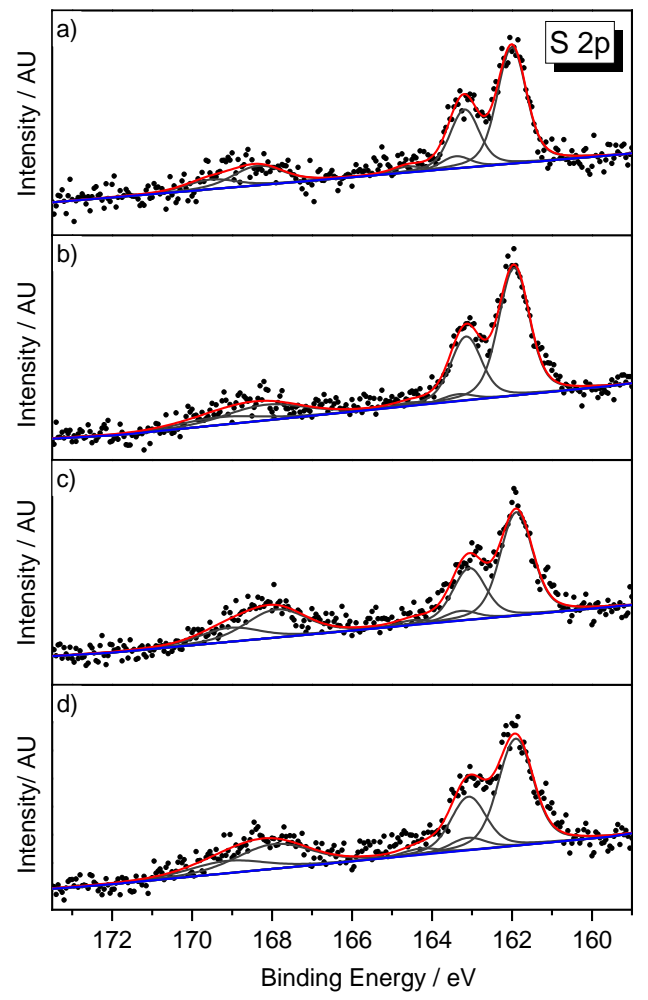

Figure S2. High-resolution S 2p XP spectra of a) freshly prepared ss $(\mathrm{dCdG})_{20}-65 \%$ and $b$ ) $\mathrm{ds}(\mathrm{dCdG})_{20}-65 \%$ monolayers and ds $(\mathrm{dCdG})_{20}-65 \%$ SAM stored for 4 weeks in c) $\mathrm{H}_{2} \mathrm{O}$ and d) $0.1 \mathrm{M}$ ectoine solution.

The S 2p high-resolution XP spectra of $(\mathrm{dCdG})_{20}-65 \%$ monolayers on the Au surface show a well resolved doublet at the binding energy $E_{\mathrm{B}}=161.9$ and $E_{\mathrm{B}}=163.1 \mathrm{eV}$ (Figure S2). $E_{\mathrm{B}}$ of these two lines corresponds to thiolate species. ${ }^{1}$ The deconvolution of the $\mathrm{S} 2 \mathrm{p}$ line shows that within these two photoemission lines a second, weak doublet at $E_{\mathrm{B}}=163.2$ and $E_{\mathrm{B}}=164.4 \mathrm{eV}$ is present in the spectra. This doublet is assigned to the $\mathrm{X}$-ray radiation damage of the thiolate species in the SAM. ${ }^{2}$ In addition, each $\mathrm{S} 2 \mathrm{p}$ photoemission spectrum shows another doublet at $E_{\mathrm{B}}=167.9$ and $E_{\mathrm{B}}=169.1 \mathrm{eV}$. The full width at half maximum (fwhm) is equal to $1.8 \pm 0.3$ $\mathrm{eV}$. This broad doublet is assigned to the $\mathrm{SO}_{\mathrm{x}}$ species with multiple oxidation states of the $\mathrm{S}$ atom. ${ }^{1}$ Already in the freshly prepared monolayer, the content of oxidized S species is close to $20 \%$. During 4 weeks of samples storage in solution, the percent of oxidized S increased to 30 $\%$. Thus, over 4 weeks of the monolayer storage in aqueous solution to content of oxidized S increased by $\sim 10 \%$. For example, in alkanethiols monolayers adsorbed on the Au surface and storied for one week in air, the content of oxidized S species increased up to $90 \%{ }^{1}$ To further monitor the stability of the $\mathrm{ds}(\mathrm{dCdG})_{20}$ and $\mathrm{ds}(\mathrm{dCdG})_{20}-65 \%$ SAMs electrochemical studies of 
the monolayer capacitance were performed. Over 21 days of the monolayer storage in solution, the capacitance minimum of the $\mathrm{ds}(\mathrm{dCdG})_{20}-65 \%$ monolayer increased from 5.4 to $5.9 \mu \mathrm{F} \mathrm{cm}-$ ${ }^{2}$. No significant changes in the monolayer capacitance indicate that the surface coverage of the gold surface with the dsDNA and $\mathrm{SC}_{6} \mathrm{OH}$ molecules did not change over time. It is consistent with the small increase in the content of oxidized $\mathrm{S}$ species and confirms that the dsDNA SAMs stored in aqueous solutions were stable. Based on these experimental results we concluded that the storage of the $(\mathrm{dCdG})_{20}-65 \%$ monolayer in aqueous solution leads neither to a fast oxidation nor desorption of the adsorbed thiolates, enabling time-dependent studies of the ectoine impact on the dsDNA structure. 
Low frequency modes have a complex behavior complicating the band assignment. The vibrational behavior of $3 \mathrm{C} 5$ in the absence of ectoine at $1035 \mathrm{~cm}^{-1}$ and $1056 \mathrm{~cm}^{-1}$ is shown in Figures S3 and S4, respectively. To these modes contribute $v(\mathrm{C}-\mathrm{O}-\mathrm{C})$ in ribose, which is coupled to $v(\mathrm{C}-\mathrm{O}[\mathrm{P}])$ mode in the phosphate ester group.

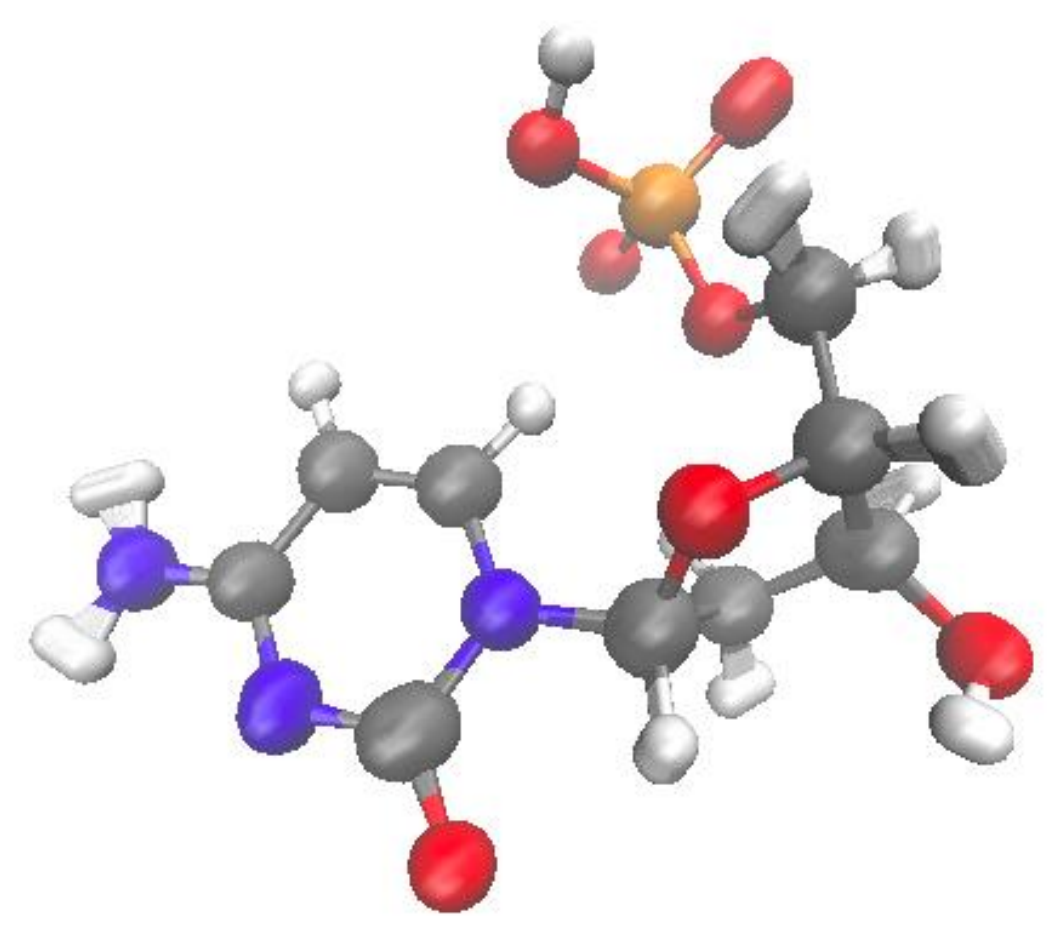

Figure S3. Molecular vibrations of 3C5 leading to the computed peak position at $1056 \mathrm{~cm}^{-1}$. Carbon atoms are colored gray, nitrogen atoms blue, hydrogen atoms white, oxygen atoms red and the phosphorus atom orange. 


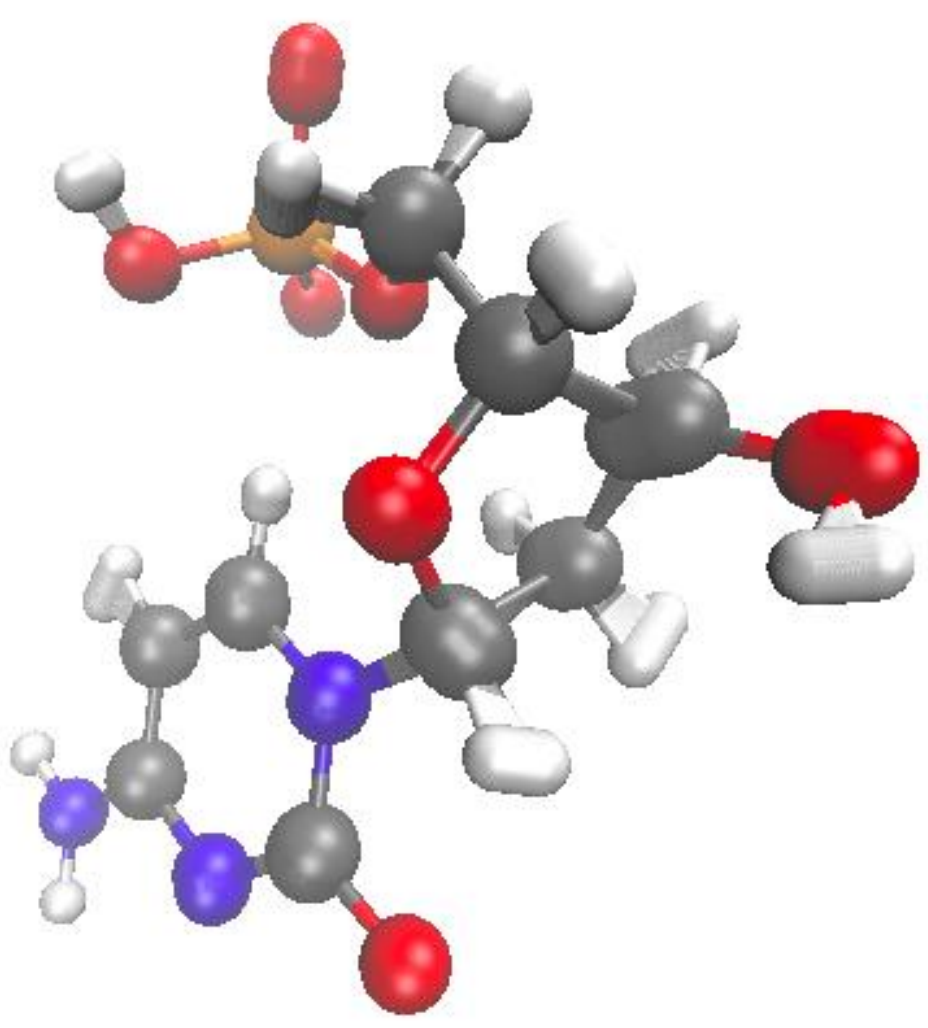

Figure S4. Molecular vibrations of 3C5 leading to the computed peak position at $1035 \mathrm{~cm}^{-1}$. Carbon atoms are colored gray, nitrogen atoms blue, hydrogen atoms white, oxygen atoms red and the phosphorus atom orange. 
S3. PM IRRA spectra of dsDNA monolayers in the absence and presence of ectoine in phosphate buffer solution

Figure $\mathrm{S} 5$ shows the spectra of the $\mathrm{ds}(\mathrm{dCdG})_{20}$ and $\mathrm{ds}(\mathrm{dCdG})_{20}-65 \%$ in monolayers stored for 2 weeks in phosphate buffer solution $(10 \mathrm{mM}, \mathrm{pH} 7)$. Time-dependent spectral changes are similar to those observed in $\mathrm{H}_{2} \mathrm{O}$. However, these changes are slower, indicating that the presence of counterions has a stabilizing effect on the hybridization, hydration, conformation and orientation of dsDNA fragments in monolayer assemblies.
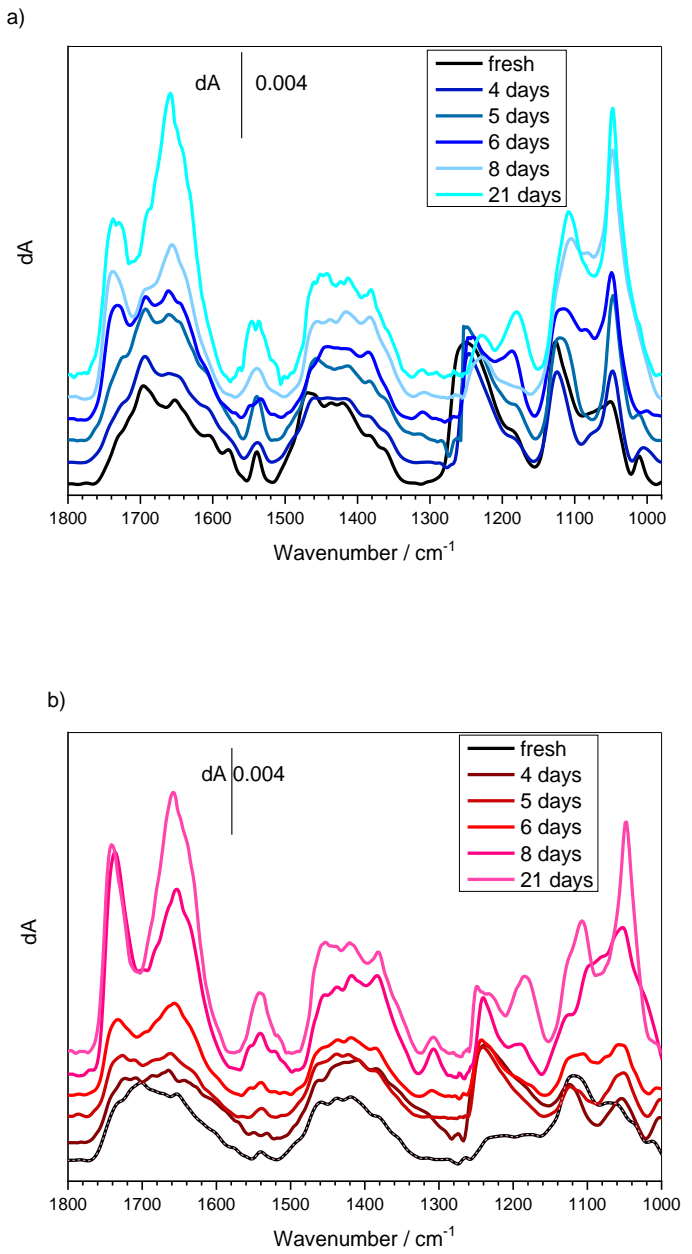

Figure S5. PM IRRA spectra in the $1800-900 \mathrm{~cm}^{-1}$ spectral region of $\mathrm{ds}(\mathrm{dGdC})_{20}$ and b) $\mathrm{ds}(\mathrm{dGdC})_{20}-65 \%$ monolayers adsorbed on Au surface stored in phosphate buffer solution (10 $\mathrm{mM}, \mathrm{pH} 7$ ) as a function of time as marked in the figure. 
Figure $\mathrm{S} 6$ shows the spectra of $\mathrm{ds}(\mathrm{dCdG})_{20}$ and $\mathrm{ds}(\mathrm{dCdG})_{20}-65 \%$ in monolayers interacting with $0.1 \mathrm{M}$ ectoine in phosphate buffer solution (10 mM, $\mathrm{pH} 7)$.
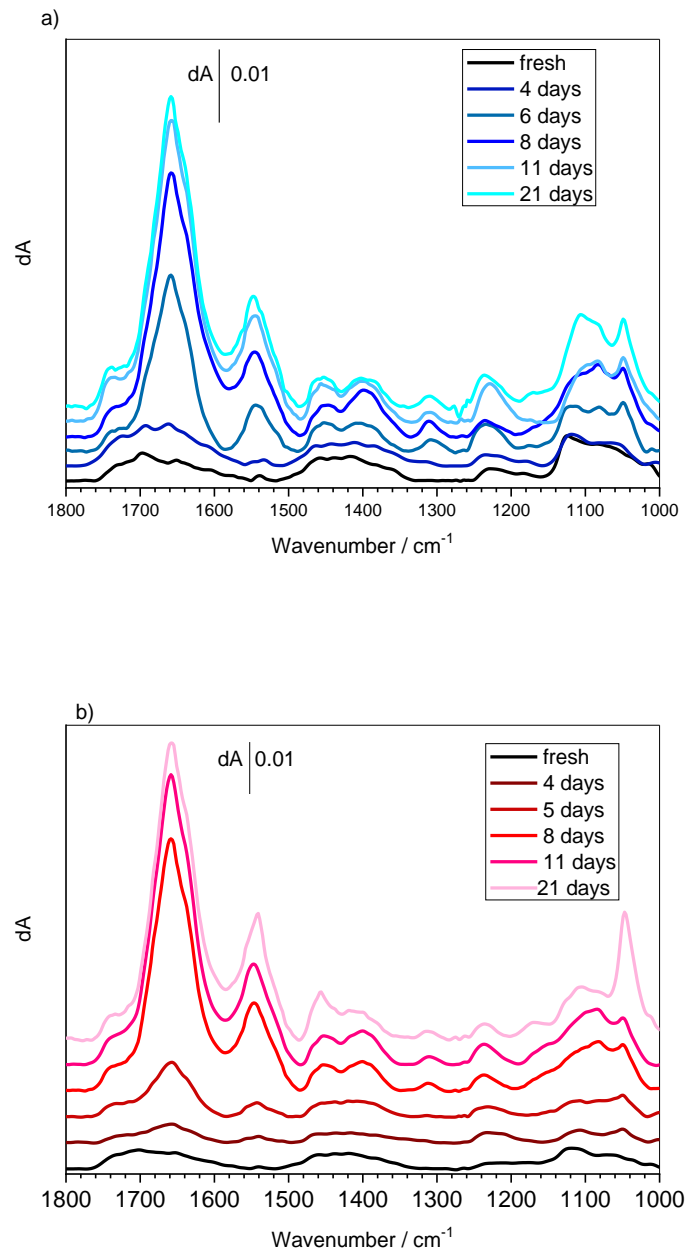

Figure S6. PM IRRA spectra in the $1800-1000 \mathrm{~cm}^{-1}$ spectral region of a) ds $(\mathrm{dGdC})_{20}$ and b) $\mathrm{ds}(\mathrm{dGdC})_{20}-65 \%$ adsorbed on Au surface stored in $0.1 \mathrm{M}$ ectoine in phosphate buffer solution $(10 \mathrm{mM}, \mathrm{pH} 7)$ as a function of time as marked in the figure.

The spectral changes in the base stacking, glycosidic and phosphate backbone frequency regions of the dsDNA molecules stored in phosphate buffer are similar to those observed in pure water. 
The IR absorption spectrum of dsDNA is very complex. To deconvolute the overlapped IR absorption modes in the spectral regions originating from base stacking, glycosidic and phosphate vibrations second derivative and Fourier self-deconvolution procedures were used. ${ }^{3}$ The minima in the second derivative spectra provided the number and positions of the of IR absorption modes contributing to each spectrum. Next, the Fourier self-deconvolution procedure was used. The deconvolution was done by using Lorenz profile function. The FWHM of the deconvoluted modes was set to $18 \mathrm{~cm}^{-1}$. Both procedures gave a good overlap of the number and positions of the deconvoluted modes. Results of both deconvolution procedures were used to deconvolute experimental PM IRRA spectra.

Figure S7 shows the experimental PM IRRA and Fourier self-deconvoluted spectra of the freshly prepared $\mathrm{ds}(\mathrm{dCdG})_{20}$ and $\mathrm{ds}(\mathrm{dCdG})_{20}-65 \%$ monolayers.

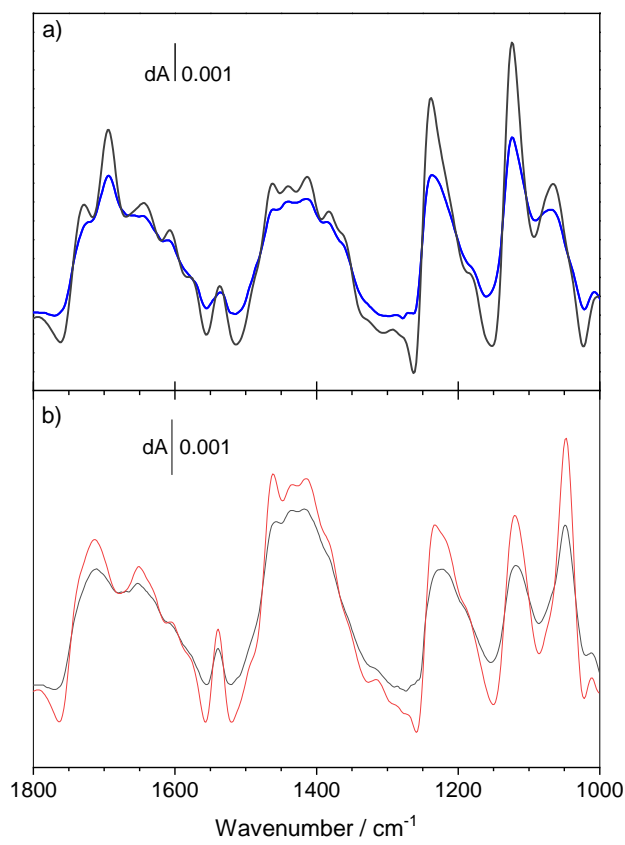

Figure S7. PM IRRAS (color line) and Fourier self-deconvolution (black line) spectra of the fresh a) $\mathrm{ds}(\mathrm{dCdG})_{20}$ and b) $\mathrm{ds}(\mathrm{dCdG})_{20}-65 \%$ in monolayers on the gold surface. 
S5. Assignment of the deconvoluted IR absorption modes of dsDNA fragments in monolayers on the gold surface

Tables S1 and S2 list IR absorption modes in the $1800-900 \mathrm{~cm}^{-1}$ spectral region of freshly prepared and stored in $\mathrm{H}_{2} \mathrm{O}$ for 11 days $(\mathrm{dCdG})_{20}$ and $(\mathrm{dCdG})_{20}-65 \%$ in monolayers selfassembled on the gold surface, respectively.

Table S1. Wavenumbers and assignment of the IR absorption modes in the $1800-900 \mathrm{~cm}^{-1}$ spectral region of freshly prepared and 11-day-old $(\mathrm{dCdG})_{20}$ monolayer on the Au surface.

\begin{tabular}{|c|c|c|c|}
\hline \multirow[t]{2}{*}{$\begin{array}{l}\text { dsDNA } \\
\text { monolayer }\end{array}$} & \multicolumn{2}{|c|}{$\begin{array}{l}\text { Wavenumber of the IR } \\
\text { absorption mode/ } \mathrm{cm}^{-1}\end{array}$} & \multirow[t]{2}{*}{ Band assignment / Reference } \\
\hline & fresh & 11-day-old & \\
\hline \multirow[t]{16}{*}{$(\mathrm{dCdG})_{20}$} & 1730 & 1735 & $v(\mathrm{C} 6=\mathrm{O} 6)_{\mathrm{G}} /{ }^{4}$ \\
\hline & 1697 & 1688 & $v(\mathrm{C}=\mathrm{O})$ in $\mathrm{GC}$ bp $/{ }^{4}$ \\
\hline & 1649 & 1656 & $\delta\left(\mathrm{NH}_{2}\right)$ in $\mathrm{GC} \mathrm{bp} / 4$ \\
\hline & & 1630 & \\
\hline & 1602 & & \\
\hline & 1576 & & \\
\hline & 1538 & 1539 & $\delta\left(\mathrm{NH}_{2}\right)+v(\mathrm{C}=\mathrm{C})+v(\mathrm{C}=\mathrm{N})$ \\
\hline & 1459 & 1458 & $\delta\left(\mathrm{NH}_{2}\right)+v(\mathrm{C}=\mathrm{C})+v(\mathrm{C}=\mathrm{N})$ \\
\hline & 1438 & & \\
\hline & 1414 & 1422 & $\begin{array}{l}v(\mathrm{C}-\mathrm{N}) \text { of the deoxyribose nucleic } \\
\text { acid linkage in anti conformation of } \\
\text { the glycosidic bond in A and B } \\
\text { conformations of DNA } \mathrm{DN}^{5-7}\end{array}$ \\
\hline & 1384 & 1384 & $\begin{array}{l}v(\mathrm{C}-\mathrm{N}) \text { of the deoxyribose nucleic } \\
\text { acid linkage in anti conformation of } \\
\text { the glycosidic bond } / 5\end{array}$ \\
\hline & 1232 & 1227 & $v_{\text {as }}\left(\mathrm{PO}_{2}^{-}\right)$, A conformation \\
\hline & 1192 & 1195 & $\begin{array}{l}\text { Sugar-phosphate vibration with a } \\
\text { high contribution of the } v(\mathrm{C} 3-\mathrm{O} 1) \text { in } \\
\text { C3'-endo conformation, appearing } \\
\text { only in dsDNA, position } \\
\text { characteristic to A conformation / } \\
{ }^{8-9}\end{array}$ \\
\hline & 1122 & 1107 & $v(\mathrm{C} 5-\mathrm{O} 4)+v_{\mathrm{s}}\left(\mathrm{PO}_{2}^{-}\right) / 10$ \\
\hline & 1073 & 1076 & $v_{\mathrm{s}}\left(\mathrm{PO}_{2}^{-}\right)$ \\
\hline & 1055 & 1047 & $\begin{array}{l}v(\mathrm{C}-\mathrm{O}[\mathrm{P}]) \text { phosphate ester stretching } \\
\text { mode } /^{8}\end{array}$ \\
\hline
\end{tabular}


Table S2. Wavenumbers and assignment of the IR absorption modes in the $1800-900 \mathrm{~cm}^{-1}$ spectral region of freshly prepared and 11-day-old (dCdG) ${ }_{20}-65 \%$ monolayer on the $\mathrm{Au}$ surface.

\begin{tabular}{|c|c|c|c|}
\hline \multirow[t]{2}{*}{$\begin{array}{l}\text { dsDNA } \\
\text { monolayer }\end{array}$} & \multicolumn{2}{|c|}{$\begin{array}{l}\text { Wavenumber of the IR } \\
\text { absorption mode/ } \mathrm{cm}^{-1}\end{array}$} & \multirow[t]{2}{*}{$\begin{array}{l}\text { Band assignment / Reference } \\
\text { dsDNA monolayer }\end{array}$} \\
\hline & fresh & 11-day-old & \\
\hline \multirow[t]{17}{*}{$(\mathrm{dCdG})_{20}-65 \%$} & 1712 & & $\mathrm{v}(\mathrm{C}=\mathrm{O} 4)_{\mathrm{T}}$ in $\mathrm{AT} \mathrm{bp} /{ }^{4}$ \\
\hline & & 1732 & $\begin{array}{l}v(\mathrm{C}=\mathrm{O} 4)_{\mathrm{T}} \text { disturbed base stacking to } \\
\mathrm{A} /{ }^{4}\end{array}$ \\
\hline & 1693 & & $\begin{array}{l}v(\mathrm{C}=\mathrm{O} 2)_{\mathrm{T}} \text { in } \mathrm{AT} \text { bp } v(\mathrm{C}=\mathrm{O}) \text { in } \mathrm{GC} \\
\mathrm{bp} /{ }^{4}\end{array}$ \\
\hline & 1655 & 1655 & $\delta\left(\mathrm{NH}_{2}\right)$ in $\mathrm{AT}$ and $\mathrm{GC}$ bps $/ 4$ \\
\hline & & 1629 & $\delta\left(\mathrm{NH}_{2}\right)+v(\mathrm{C}=\mathrm{C})+v(\mathrm{C}=\mathrm{N})$ \\
\hline & 1596 & & $\delta\left(\mathrm{NH}_{2}\right)$ in $\mathrm{AT}$ bp $/ 4$ \\
\hline & 1576 & & $\begin{array}{l}\delta\left(\mathrm{NH}_{2}\right) \text { in disturbed, weakly } \\
\text { hydrogen bonded AT bp / }\end{array}$ \\
\hline & 1539 & 1539 & $\delta\left(\mathrm{NH}_{2}\right)+v(\mathrm{C}=\mathrm{C})+v(\mathrm{C}=\mathrm{N})$ \\
\hline & 1464 & 1456 & $\begin{array}{l}\delta\left(\mathrm{NH}_{2}\right)+v(\mathrm{C}=\mathrm{C})+v(\mathrm{C}=\mathrm{N})+ \\
\text { coupled adenine -ribose vibrations } / \\
7\end{array}$ \\
\hline & 1412 & 1422 & $\begin{array}{l}v(\mathrm{C}-\mathrm{N}) \text { of the deoxyribose nucleic } \\
\text { acid linkage in anti conformation in } \\
\mathrm{A} \text { and } \mathrm{B} \text { conformations of } \mathrm{DNA}^{5-7}\end{array}$ \\
\hline & 1385 & 1386 & $\begin{array}{l}v(\mathrm{C}-\mathrm{N}) \text { of the deoxyribose nucleic } \\
\text { acid linkage in anti conformation of } \\
\text { the glycosidic bond } / 5\end{array}$ \\
\hline & 1239 & 1246 & $v_{\mathrm{as}}\left(\mathrm{PO}_{2}^{-}\right), \mathrm{A}$ conformation \\
\hline & 1223 & & $v_{\mathrm{as}}\left(\mathrm{PO}_{2}^{-}\right), \mathrm{B}$ conformation \\
\hline & 1193 & 1188 & $\begin{array}{l}\text { Sugar-phosphate vibration with a } \\
\text { high contribution of the } v(\mathrm{C} 3-\mathrm{O} 1) \text { in } \\
\text { C3'-endo conformation, appearing } \\
\text { only in dsDNA, position } \\
\text { characteristic to A conformation / } \\
{ }^{8-9}\end{array}$ \\
\hline & 1115 & 1103 & $v(\mathrm{C} 5-\mathrm{O} 4)+v_{\mathrm{s}}\left(\mathrm{PO}_{2}^{-}\right) / 10$ \\
\hline & 1074 & 1075 & $v_{\mathrm{s}}\left(\mathrm{PO}_{2}^{-}\right)$ \\
\hline & 1050 & 1047 & $\begin{array}{l}v(\mathrm{C}-\mathrm{O}[\mathrm{P}]) \text { phosphate ester stretching } \\
\text { mode } /^{8}\end{array}$ \\
\hline
\end{tabular}


Figure S8 shows raw PM IRRA spectra of fresh $\mathrm{ds}(\mathrm{dCdG})_{20}$ and $\mathrm{ds}(\mathrm{dCdG})_{20}-65 \%$ in monolayers on the Au surface.

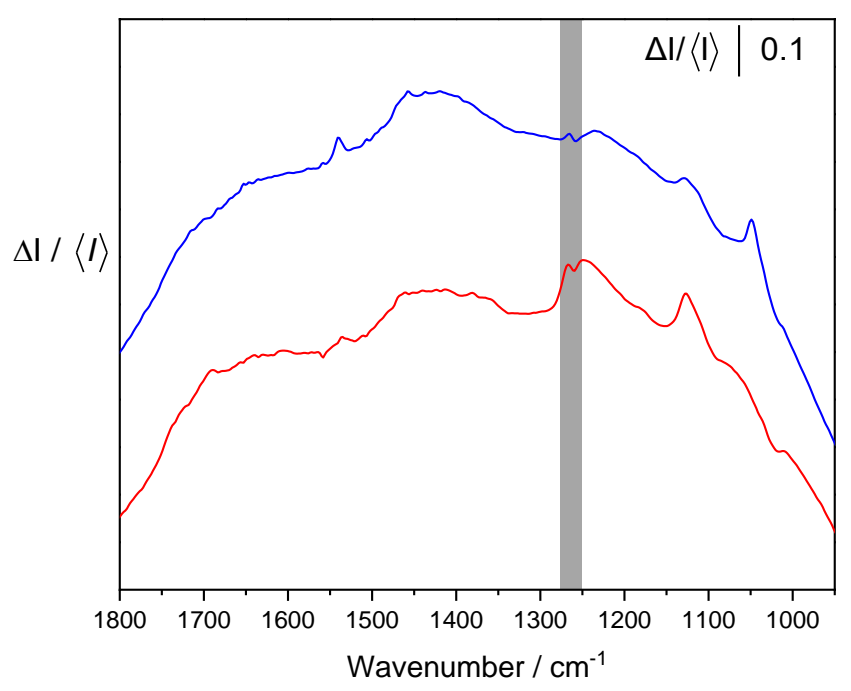

Figure S8. Raw $\Delta I /\langle I\rangle$ PM IRRA spectra of ds $(\mathrm{dCdG})_{20}$ and $\mathrm{ds}(\mathrm{dCdG})_{20}-65 \%$ monolayers on the Au surface.

Regardless of the presence of a monolayer on the gold surface, in the $1260-1240 \mathrm{~cm}^{-1}$ region, the raw PM IRRA spectra $(\Delta I /\langle I\rangle)$ display a step in the background intensity. The presence of this step complicates the background correction of the second order Bessel function of the PM IRRA spectra. Despite this fact, the IR absorption modes originating from an analyzed sample can be extracted. 
In PM IRRAS, the integral intensity of a given IR absorption mode is proportional not only to the surface concentration of the adsorbed species $(\Gamma)$ but also the square of the absolute value of the dot product of the transition dipole moment vector changes during the normal vibration $\vec{\mu}^{\prime}$ and the electric field vector of the p-polarized light $\vec{E}^{11-12}$ :

$$
I=\int A d v \cong \Gamma\left|\vec{\mu}^{\prime}\right|^{2}\langle\vec{E}\rangle^{2} \cos ^{2} \theta
$$

where $\theta$ is the angle between the $\vec{\mu}^{\prime}$ and $\vec{E}$ vectors. According, to equation S1 the integral intensity of an IR absorption mode depends on the value of the $\theta$ angle. In PM IRRAS, the $\vec{E}$ vector of the p-polarized light is oriented normal to the mirror surface. In a monolayer assembly, the dsDNA fragments have the same (similar) orientation, indicating that the $\vec{\mu}^{\prime}$ vector of a given normal vibration has well-defined orientation in a studied film. Figure S9 illustrates this relationship.

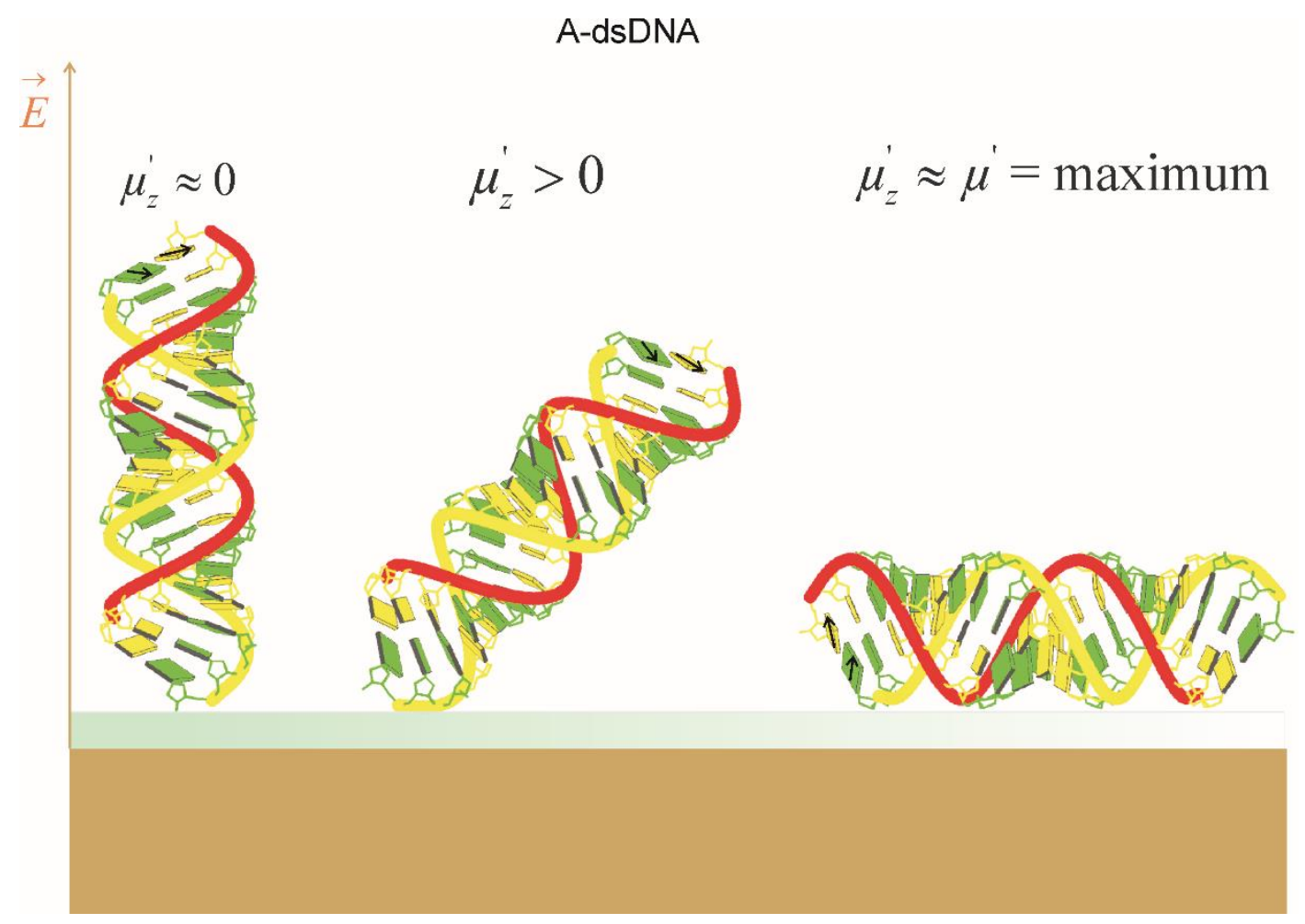

Figure S9. Cartoon showing different orientations of A-dsDNA fragments adsorbed in the $\mathrm{Au}$ surface via a thiol linkage. The long axis of the A-dsDNA is tilted by $0^{\circ}, 45^{\circ}$, and $90^{\circ}$ tilted with respect to the surface normal. The orange arrow shows the direction of the electric field 
vector and the black arrows indicate orientations of the transition dipole vectors of $v(C=O)$ and ring stretching modes in base stacking modes region.

The integral intensity of the IR absorption modes originating from the nucleic acid bases depends on the orientation of the $\vec{E}$ with respect to the $\vec{\mu}^{\prime}$ vector (Eq. S1). In PM IRRAS, the $\vec{E}$ vector has a normal to the metal surface orientation. The transition dipole vector change of the $v(\mathrm{C}=\mathrm{O})$ and in plane stretching modes are located parallel to the plane of the aromatic rings of the nucleic acid bases. ${ }^{4}$ In C, G. A and T nucleic acids bases these vectors have different orientations versus each other. Their tilt reflects the tilt and twist of the base planes. It can be correlated with the tilt of the helix axis. Thus, when the long axis of a dsDNA fragment is oriented parallel to the $\vec{E}$ vector, the normal component of the $\vec{\mu}^{\prime}$ vectors (marked with a black arrow in Figure S9) is close to zero and the integral intensities of the IR absorption modes in the base stacking modes region are attenuated. A gradual tilt of the long axis of the double helix causes an increase in normal component of the $\vec{\mu}^{\prime}$ vector. According to equation S1 the integral intensity of these modes increases reaching a maximum when $\vec{\mu}^{\prime}=\vec{\mu}_{z}^{\prime}$. This situation corresponds to an almost perpendicular to the $\vec{E}$ vector orientation of the long axis of the dsDNA helix (Figure S9).

\section{References:}

1. Schoenfisch, M. H.; Pemberton, J. E., Air stability of alkanethiol self-assembled monolayers on silver and gold surfaces. J. Am. Chem. Soc. 1998, 120 (18), 4502-4513.

2. Zubrägel, C.; Deuper, C.; Schneider, F.; Neumann, M.; Grunze, M.; Schertel, A.; Wöll, C., The presence of two different sulfur species in self-assembled films of n-alkanethiols on Au and Ag surfaces. Chem. Phys. Lett. 1995, 238 (4-6), 308-312.

3. Ochiai, S., Computer processing of measured infrared spectra. In Introduction to experimental infrared spectroscopy, Tasumi, M., Ed. Wiley: Chichester, 2015; pp 8396.

4. Lee, C.; Park, K. H.; Cho, M., Vibrational dynamics of DNA. I. Vibrational basis modes and couplings. J. Chem. Phys. 2006, 125 (11), 114508-1 - 114508-16.

5. Adam, S.; Liquier, J.; Taboury, J. A.; Taillandier, E., Right- and left-handed helixes of poly[d(A-T) $]^{*}$ Poly[d(A-T)] investigated by infrared spectroscopy. Biochemistry 1986, $25,3220-3225$. 
6. Liquier, J.; Taillander, E., Infrared Spectroscopy of Nucleic Acids. In Infrared Spectroscopy of Biomolecules, Mantsch, H. H.; Chapman, D., Eds. Wiley-Liss: New York, 1996.

7. White, A. P.; Reeves, K. K.; Snyder, E.; Farrell, J.; Powell, J. W.; V., M.; Griffey, R. H.; H., S., Hydration of single-stranded phosphodiester and phosphorothioate oligodeoxyribonucleotides. Nucleic Acids Res. 1996, 24 (16), 3261-3266.

8. Whelan, D. R.; Bambery, K. R.; Heraud, P.; Tobin, M. J.; Diem, M.; McNaughton, D.; Wood, B. R., Monitoring the reversible B to A-like transition of DNA in eukaryotic cells using Fourier transform infrared spectroscopy. Nucleic Acids Res. 2011, 39 (13), 5439-5448.

9. Pohle, W.; Fritzsche, H., A new conformation-specific infrared band of A-DNA in films. Nucleic Acids Res. 1980, 8 (11), 2527-2535.

10. Lu, K. C.; Prohofsky, E. W.; van Zandt, L. L., Vibrational modes of A-DNA, B-DNA, and A-RNA backbones: an application of a green-function refinement procedure. Biopolymers 1977, 16, 2491-2506.

11. Allara, D. L.; Nuzzo, R. G., Spontaneously organized molecular assemblies. 2. Quantitative infrared spectroscopic determination of equilibrium structures of solution - adsorbed n-alkanoic acids on an oxidized aluminum surface. Langmuir 1985, 1, 5266.

12. Zamlynny, V.; Lipkowski, J., Quantitative SNIFTIRS and PM IRRAS of organic molecules at electrode surfaces. In Advances in electrochemical science and engineering, Alkire, R. C.; Kolb, D. M.; Lipkowski, J.; Ross, P. N., Eds. Wiley-VCH: Weinheim, 2006; Vol. 9, pp 315-376. 